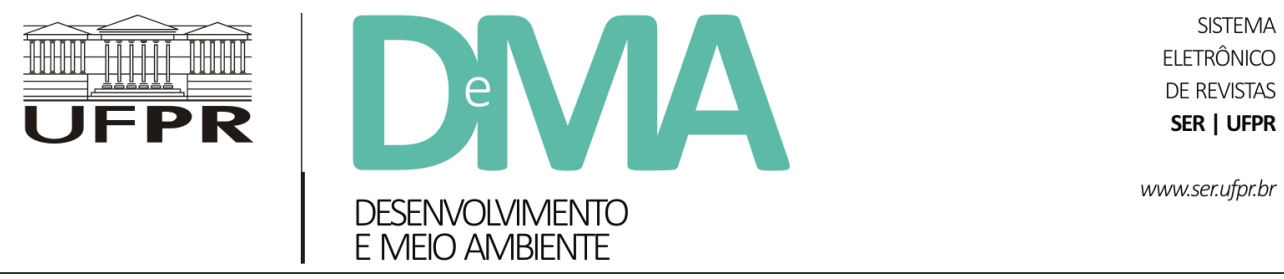

\title{
Libertar para desenvolver: os grandes empreendimentos e o "des-envolvimento" na comunidade tradicional do Cumbe, Ceará, Brasil
}

\section{Free to develop: the great enterprises and the "development" in the traditional community of Cumbe, Ceará, Brazil}

\author{
Anderlany Aragão dos SANTOS ${ }^{1 *}$, Amanda Stefanie Sérgio da SILVA ${ }^{1}$, Cimone ROZENDO $^{1}$ \\ ${ }^{1}$ Universidade Federal do Rio Grande do Norte (UFRN), Natal, RN, Brasil. \\ *E-mail de contato: lanyaragao5@gmail.com
}

Artigo recebido em 6 de setembro de 2017, versão final aceita em 15 de março de 2018.

RESUMO: A privação das liberdades limita as escolhas e as oportunidades das pessoas, segundo Amartya Sen. Assim, a eliminação dessas privações constitui o meio de garantir o exercício do papel de agente dos indivíduos, tornando a liberdade o principal fim do desenvolvimento. A liberdade, nessa concepção, está condicionada à melhoria da alimentação, à atuação política e ao acesso à saúde, à educação e ao saneamento. Desse modo, este artigo objetivou investigar que liberdades são potencializadas, ou limitadas, com a instalação de empreendimentos eólicos e de carcinicultura em uma comunidade tradicional, quilombola e pesqueira, situada no nordeste brasileiro: a Comunidade do Cumbe/CE. Por meio de dois fieldworks e entrevistas com residentes, foram observadas restrições às liberdades comunitárias. Além disso, foram relatadas privatizações de espaços de subsistência, negligência aos aspectos de saneamento e implicação de riscos à saúde da comunidade. Destaca-se, ainda, a repressão às liberdades políticas, ilustrada em episódios nos quais a população foi coagida, intimidada e criminalizada devido ao enfrentamento das injustiças ambientais ocasionadas pelos empreendimentos. Mostra-se necessário, portanto, problematizar o tipo de desenvolvimento levado a tais comunidades, tendo em vista que este pode ilustrar o progresso econômico de grupos empresariais em detrimento dos modos de vida tradicionais, subalternizando-os e os tornando invisíveis, tal como foi diagnosticado na Comunidade do Cumbe.

Palavras-chave: desenvolvimento como liberdade; impactos socioambientais; grandes empreendimentos; comunidade quilombola.

ABSTRACT: According to Amartya Sen, the deprivation of freedom limits the people's choices and opportunities. Thus, 
in order to guarantee the exercise of individuals as agents is necessary to eliminate such deprivation, making freedom the main purpose of development. Freedom, in this way, is related to the improvement on food conditions, political action, health, education and sanitation access. With this in mind, this article aims to investigate which freedom is potentialized or limited by the installation of wind towers and shrimp farms in a traditional quilombola fishing community, which is located in the state of Ceará, Brazil - the Cumbe community. The restrictions on the community freedom were observed through two fieldworks and interviews with residents. Additionally, there have been reports of privatizations of livelihoods, neglecting of sanitation aspects implicating on community health risks. It was also highlighted the repression of political freedom, illustrated in episodes in which the population was coerced, intimidated and criminalized while facing the environmental injustices caused by the enterprises. Hence, it is necessary to problematize the type of development in the traditional communities, since this development can illustrate the economic progress of entrepreneurs groups at the expense of the traditional ways of life, subalternizing and making the communities invisible, as it was diagnosed in the Cumbe community.

Keywords: development as freedom; social and environmental impacts; large enterprises; quilombola community.

\section{Introdução}

A literatura sobre o conceito de desenvolvimento apresenta uma multiplicidade de abordagens com diferentes nuances. De forma geral, e em que pese tais diferenças, é possível sintetizar duas correntes de desenvolvimento. Uma tem no crescimento econômico um lugar central como estratégia de desenvolvimento, o qual levaria espontaneamente à melhoria dos padrões sociais, conforme a maior distribuição dos recursos econômicos, desencadeada após um momento inicial de concentração de renda. Já a outra aponta a insuficiência dessa proposição e afirma que o crescimento é apenas um componente do desenvolvimento, que engloba outras estratégias fundamentais, como os aspectos sociais, culturais, ambientais e institucionais (Furtado, 1974; Sen, 2000; Sachs, 2008; Veiga, 2008).

Adjetivações como ecodesenvolvimento e desenvolvimento sustentável, por exemplo, são evidências desses esforços de reformulação conceitual, mas que ainda encontram grandes dificuldades de serem incorporados efetivamente, como prática política, aos projetos de desenvolvimento. Sobre esse aspecto, Sachs (2008) afirma que prevalece uma visão de desenvolvimento pautada em um fundamentalismo mercantil e em receitas inspiradas em uma visão idealizada de globalização. Esse fundamentalismo desconsidera, portanto, as estratégias que não se orientam por seus pressupostos e organizam o mundo social com base em outros parâmetros, como é o caso das comunidades tradicionais, objeto de análise deste artigo.

No Brasil, as comunidades tradicionais constituem grupos que têm formas próprias de organização social e se autoreconhecem. Esses grupos também são reconhecidos por serem diferenciados da lógica socioeconômica e cultural das sociedades urbano-industriais e utilizam os recursos ecossistêmicos, regidos por seus próprios costumes ou alguma legislação especial, por meio de práticas tradicionais e inovações (Diegues \& Arruda, 1999; Brasil, 2004; Brasil, 2007).

As práticas dessas populações têm assegurado, ao longo dos anos, a manutenção dos recursos ecossistêmicos de onde se situam. Em geral, localizam-se em áreas de pouco interesse do capital e foram historicamente alijadas dos processos mais gerais 
de desenvolvimento (Rozendo, 2006), aspecto que também contribui para a manutenção da qualidade ambiental do lugar. Entretanto, devido a pressões crescentes pela inserção de tais povos na lógica hegemônica (Diegues \& Arruda, 1999), chegam aos territórios tradicionais grandes empreendimentos, justificados por discursos desenvolvimentistas baseados em noções de progresso e crescimento econômico.

Tais projetos trazem consigo uma visão meramente quantitativa do desenvolvimento e ignoram aspectos sociais, culturais e ambientais (Mattedi, 2015). Nessa perspectiva, "des-envolver" significa criar um outro envolvimento (Porto-Gonçalves, 2004), orientado por uma racionalidade econômica divergente, na maioria dos casos, das formas que organizam as comunidades tradicionais, o que é, frequentemente, motivo de tensões. Desse contexto, decorrem a tentativa e a necessidade de descredibilizar as estratégias dessas populações, subalternizá-las, causando aquilo que Boaventura Santos (2007) denominou epistemicídio.

A abordagem adotada neste estudo compreende que o crescimento econômico é apenas um meio para obtenção da melhoria da qualidade de vida da população, a qual depende de outros fatores, como disposições sociais, econômicas e direitos civis (Sen, 2000). Tomar o crescimento econômico como o objetivo do desenvolvimento é uma visão simplista e desvia as atenções da tarefa básica de identificação das necessidades fundamentais da coletividade, para concentrá-la em objetivos abstratos, centrados em números (Furtado, 1974). Portanto, a análise do crescimento como sinônimo do desenvolvimento é insuficiente, tendo em vista a necessidade de se compreender também os fins de tal processo (Furtado, 1974).
De acordo com Sen (2000), o principal fim do desenvolvimento pode ser resumido na garantia do exercício do papel de agente dos indivíduos, baseado na participação ativa dos atores sociais nas ações econômicas, sociais e políticas ocorridas em seu território e na oportunidade de ocasionar mudanças e realizações de acordo com seus próprios valores e objetivos. A condição de agente é alcançada mediante expansão das liberdades reais de que as pessoas desfrutam. As diferentes formas de liberdade, trabalhadas por Amartya Sen, são fundamentais para a análise que se delineia aqui, com especial enfoque às liberdades instrumentais, visto que estas são o principal meio para a expansão da liberdade humana em geral e, consequentemente, para a promoção do desenvolvimento.

Para Sen (2000), a liberdade está dividida em cinco liberdades instrumentais: as liberdades políticas, as facilidades econômicas, as oportunidades sociais, as garantias de transparência e a segurança protetora. Essas liberdades, portanto, são analisadas mediante atuação política dos indivíduos diante de modificações na comunidade, parâmetros de inclusão social, oportunidade dos indivíduos na utilização de recursos econômicos, aspectos referentes à alimentação, à saúde e ao saneamento e garantias de dessegredo e clareza nos processos relacionados à dinâmica territorial (Sen, 2000).

Pautado na abordagem do desenvolvimento proposta por Sen (2000), este estudo analisou os processos desencadeados pela implantação de usinas de energia eólica e de fazendas de carcinicultura na Comunidade do Cumbe, litoral do estado do Ceará, no Brasil. O objetivo foi compreender a ação desses empreendimentos sob as diferentes formas de liberdade dos indivíduos implicados nesses processos. Considerando que grande parte dos projetos se 
justifica pela capacidade de gerar desenvolvimento, buscou-se investigar aspectos acerca das limitações ou ampliações das liberdades criadas pela instalação e pela operação dos empreendimentos.

Para tal fim, o artigo está estruturado na apresentação da área de estudo, seguida dos aspectos metodológicos do levantamento e da interpretação dos dados que constituem os resultados da pesquisa. Os resultados foram divididos com base na análise dos discursos desenvolvimentistas contidos nos estudos ambientais dos empreendimentos e, em seguida, na análise das privações das liberdades instrumentais posteriormente relacionadas, a fim de compreender as condições de execução do papel de agente dos atores sociais da comunidade investigada.

\section{Metodologia}

\subsection{Aspectos teóricos e metodológicos}

Este artigo, embora dialogue com as perspectivas de desenvolvimento de autores como Sachs, Furtado e Porto-Gonçalves, toma como eixo estruturante o conceito de desenvolvimento proposto Amartya Sen, em sua obra Desenvolvimento como liberdade (2000). Para o autor, só existe desenvolvimento à medida que se ampliam as liberdades individuais. Portanto, não se pode conceber o desenvolvimento se as condições para essa expansão não se realizam.

Para Sen (2000, p. 10), “o desenvolvimento consiste na eliminação de privações de liberdade que limitam as escolhas e as oportunidades das pessoas de exercer ponderadamente sua capacidade de agência". Essa capacidade é avaliada considerando-se as habilidades de que dispõem os indivíduos para lidar com as privações e está restrita às oportunidades sociais estabelecidas pelas sociedades. Tais oportunidades são compreendidas como disposições sociais (serviços de saúde, educação) e/ou institucionais, criadas pelo Estado ou por outras instituições da sociedade, e são fundamentais para a expansão das liberdades e, consequentemente, das capacidades. O que está em questão é a oportunidade de os indivíduos realizarem escolhas, mas não quaisquer escolhas. Assim, expandir as capacidades é proporcionar às pessoas liberdade para que possam fazer coisas e levar o tipo de vida que valorizam.

Sen (2000, p. 33) considera que "ter mais liberdade melhora o potencial das pessoas para cuidar de si mesmas e para influenciar o mundo". Trata-se de uma opção teórica que permite abordar metodologicamente o problema do desenvolvimento, para além dos clássicos indicadores centrados exclusivamente na renda. Compreender a forma como as diferentes liberdades individuais são potencializadas ou limitadas diante da implantação de grandes empreendimentos constitui um referencial fundamental para problematizar a noção de desenvolvimento veiculada por tais projetos.

$\mathrm{Na}$ abordagem de Sen (2000), o conceito de desenvolvimento abrange não somente a satisfação de necessidades básicas (materiais e intangíveis), mas incorpora, ainda, a busca de soluções politicamente descentralizadas, promotoras da inclusão social e ecologicamente prudentes, tendo em vista o esforço de valorização máxima dos recursos ambientais existentes (Sachs, 2007).

\subsection{Caracterização da área de estudo}

Como mencionado anteriormente, este estudo tem como referência empírica a comunidade 
tradicional quilombola do Cumbe, composta por cerca de 600 habitantes, distribuídos entre 162 famílias (Ribeiro, 2013). Fica situada na Área de Proteção Ambiental (APA) de Canoa Quebrada, localizada no estado do Ceará, no nordeste brasileiro

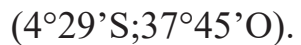

As ecozonas cumbenses ${ }^{1}$ são divididas em manguezal, rio, dunas, praia e a vila do Cumbe. Tais ecozonas estabelecem as condições para o desenvolvimento das atividades econômicas da região, nas quais o manguezal é marcado pela carcinicultura e pelas atividades tradicionais de subsistência, voltadas à coleta de crustáceos e de mariscos. No rio e na praia, é viabilizada a pesca artesanal, e nas dunas foram instaladas empresas de energia eólica e a Companhia de Água e Esgoto do Ceará (CAGECE). Além disso, em 2008 havia um projeto para a instalação de um resort ${ }^{2}$.

A instalação dos empreendimentos, com destaque à carcinicultura e às empresas eólicas (Figura 1), resultou em riscos e impactos ambientais negativos sobre as ecozonas e, consequentemente, sobre as

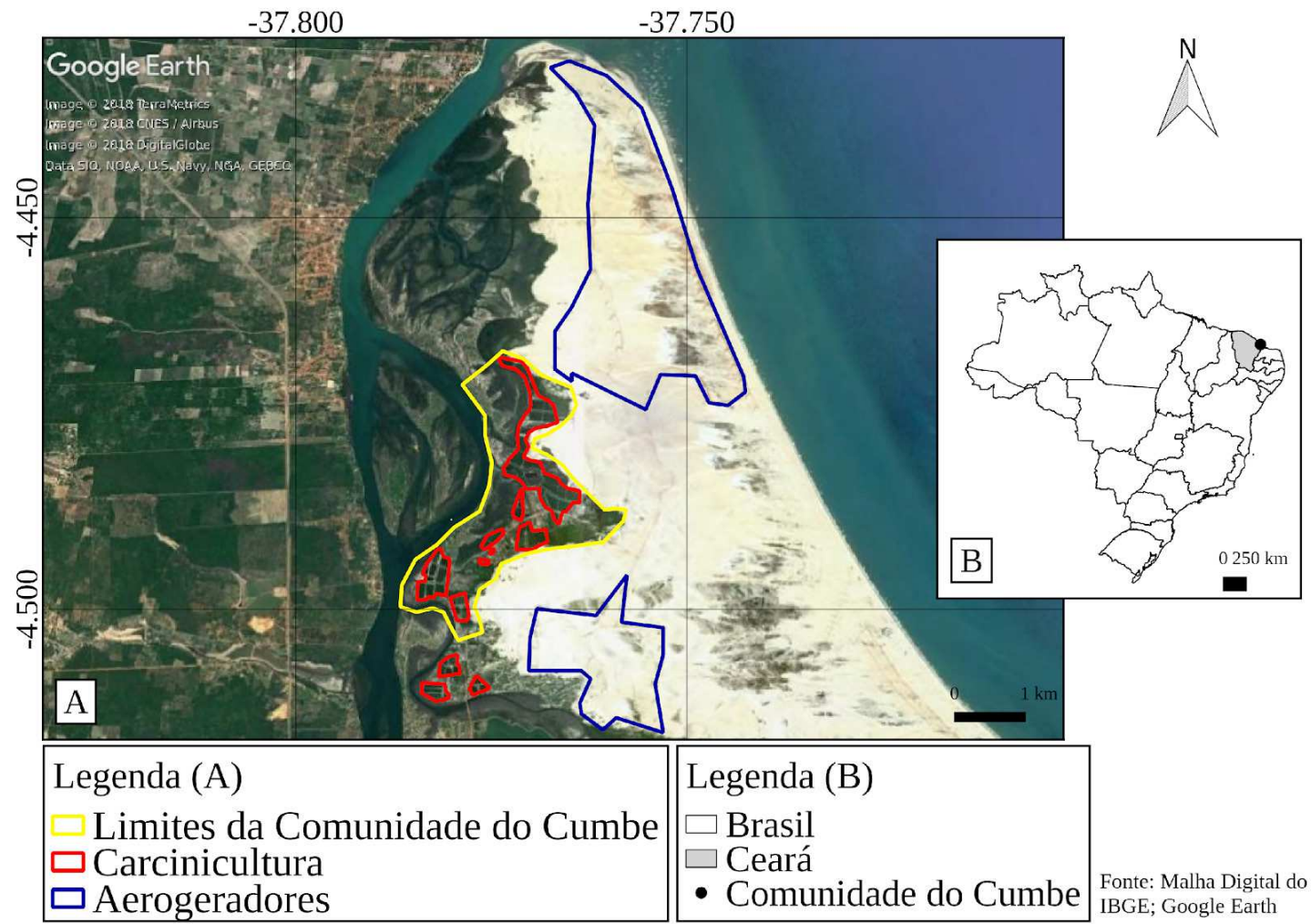

FIGURA 1 - Localização da comunidade quilombola do Cumbe e ocupação do manguezal pela carcinicultura e das dunas pelos aerogeradores. FONTE: Malha Digital do IBGE; Adaptado de Google Earth, 2017.

${ }^{1}$ Compreende-se ecozonas como unidades ecológicas caracterizadas por uma combinação particular de fatores abióticos e bióticos.

${ }^{2}$ Foi realizado um estudo de impacto ambiental (EIA) pela empresa Geoconsult com esse propósito. Como o resort não foi instalado, são considerados neste estudo apenas os discursos desenvolvimentistas que justificariam sua implantação, extraídos do EIA-RIMA. 
atividades tradicionais de subsistência (Pinto et al., 2014).

Destaca-se, ainda, que a instalação e a operação dos empreendimentos e suas consequentes modificações no modo de vida tradicional promoveram o partidarismo na comunidade, o qual se refletiu na organização política cumbense. Sinteticamente, o partidarismo pode ser caracterizado pela presença de dois grupos, dos quais um resolve guiar-se pela tradição e o outro apoia a novidade (Foster, 1962). Com isso, além dos impactos ambientais sobre as ecozonas, os grandes empreendimentos provocaram a reconfiguração da organização da comunidade, criando antagonismos internos e novas formas de solidariedade com os responsáveis pelos empreendimentos.

Desse modo, deu-se, no Cumbe, a construção de duas associações: a Associação Quilombola do Cumbe e a Associação dos Moradores do Cumbe e Canavieira. A primeira, formada por cerca de 95 famílias, comanda os movimentos de oposição aos grandes empreendimentos e aos impactos por eles ocasionados, contrapondo-se ao modelo desenvolvimentista proposto pelos empresários, e busca afirmar-se nos modos tradicionais. A segunda apoia os empreendimentos, pois compreende que estes promovem o emprego e geram renda.

Tendo isso em vista, a Comunidade do Cumbe foi escolhida como referência empírica desta análise justamente por estar em uma ecozona onde são promovidas as atividades tradicionais e concentrar grande número de conflitos decorrentes da instalação de grandes empreendimentos. Os conflitos socioambientais foram concebidos neste artigo como um aspecto que restringe as liberdades (Mello et al., 2009). Assim, dado que as liberdades instrumentais analisadas neste trabalho são condicionadas à garan- tia das liberdades substantivas, é necessária, ainda, uma breve caracterização de aspectos referentes às condições de alimentação, educação, saúde e saneamento da comunidade.

O regime alimentar da região, devido às atividades tradicionais de subsistência (pesca e catação de crustáceos e mariscos), é caracterizado pelo alto consumo de crustáceos e peixes. Além de garantir a subsistência, essas atividades asseguram renda às famílias, uma vez que os excedentes são comercializados. Tais rendimentos permitem o acesso a bens que não são produzidos na localidade. Destaca-se a aquisição de alimentos, porém são ainda adquiridos outros produtos, como roupas, calçados e bens duráveis (Nascimento, 2014).

Quanto ao acesso à saúde, a comunidade dispõe de uma única unidade básica de saúde. Segundo depoimento de moradores, o atendimento é bastante precário: faltam medicamentos e é recorrente a ausência de médicos. Os moradores relatam que, quando há disponibilidade de profissionais da saúde, são distribuídas senhas insuficientes para atender ao conjunto da população, como evidencia a entrevista a seguir:

Eu não sei nem se esse ano já teve atendimento. Só tem um posto de saúde aqui e você precisa sair 4 da manhã, porque só tem de 14 a 15 fichas. Você sai às 4 da manhã pra pegar a ficha, vai 7 horas pra dar seu nome e às 9 horas vai tentar ser atendido. (Moradora em entrevista concedida à autora em fevereiro de 2017).

Ainda acerca das liberdades substantivas, com base na análise dos índices educacionais, percebe-se um percentual significativo de pessoas com baixa ou nenhuma escolaridade. Segundo Ribeiro (2013, 
p. 81), com base na análise de uma amostra com 88 moradores da localidade, registrou-se que 52\% dos habitantes não concluiu o ensino fundamental, enquanto $11 \%$ não têm escolaridade. Tal índice pode ser justificado pela necessidade de deslocamento até o centro do município após as séries primárias, tendo em vista que a única escola da comunidade oferece apenas o nível fundamental.

Concernente ao saneamento, destaca-se a ausência de um sistema público de esgotamento sanitário que corresponda às necessidades da população. A maior parte das coletas de esgoto é feita por fossas, uma iniciativa precária devido ao tipo de solo argiloso, que causa constantes infiltrações. A coleta de lixo é feita duas vezes por semana, porém é comum a realização da queima do resíduo para, em seguida, enterrá-lo. O sistema de abastecimento de água é operado pela CAGECE em ligações domiciliares.

\subsection{Operacionalização da pesquisa}

Para a análise de tais aspectos, foram realizadas pesquisas documentais e bibliográficas, além de entrevistas semiestruturadas e observações de campo. As pesquisas bibliográficas referentes à área de estudo foram fundamentadas na seleção de artigos e teses na biblioteca de dissertações da Universidade Federal do Ceará e nas plataformas Science Direct, Research Gates e Periódicos Capes, com foco na caracterização e nos impactos ocasionados pelos empreendimentos instalados em território tradicional.

O levantamento de dados por meio documental foi realizado mediante consultas a matérias e reportagens produzidas sobre o Cumbe e divulgadas em jornais, revistas e na rede mundial de computadores (internet). Somam-se a tais documentos consultas a estudos de impacto ambiental (EIAs), relatórios de impactos ambientais (RIMAs) e relatórios ambientais simplificados (RAS), disponibilizados na biblioteca da Superintendência de Meio Ambiente do Ceará (SEMACE).

Foram realizadas, ainda, pesquisa de campo e entrevistas semiestruturadas com representantes das associações comunitárias. Tais entrevistas abordaram informações pontuais não encontradas nos estudos levantados, como a efetividade das promessas constatadas nos projetos dos empreendimentos e o acesso a postos de saúde, escolas e demais serviços públicos essenciais. Além disso, foram levantados aspectos referentes à atuação política, ao acesso aos recursos e às oportunidades econômicas.

Todas as entrevistas foram precedidas pela aplicação do Termo de Consentimento Livre e Esclarecido, em que foram contextualizados os aspectos gerais da pesquisa e os principais objetivos. O documento foi lido e assinado pelos respectivos entrevistados. Caso analfabeto, o entrevistado era informado verbalmente acerca dos objetivos do trabalho e solicitado a impor a impressão digital no documento, permitindo a gravação e a utilização dos dados levantados nas entrevistas.

Tais dados foram trabalhados por análise de conteúdo (Bardin, 2001) após as entrevistas serem transcritas pela própria pesquisadora. Posteriormente, as informações foram organizadas em quadros temáticos, os quais dividem os dados levantados de acordo com as liberdades instrumentais que representam. 


\section{Resultados e discussões}

\subsection{O discurso desenvolvimentista}

A instalação de grandes empreendimentos na região do Cumbe, justificada pelo discurso desenvolvimentista, com destaque à carcinicultura e aos parques eólicos, promoveu diversas modificações socioambientais no âmbito da comunidade. Uma dessas modificações é percepção dos moradores em relação à chegada desses empreendimentos, vista como uma ameaça à autonomia da comunidade, conforme ilustra o depoimento a seguir:

Eles [os responsáveis pela instalação da usina eólica] chegaram sem pedir licença, não bateram na nossa porta. Nós fomos ameaçados de todas as formas; os empresários diziam que estavam trazendo o desenvolvimento. Mas que desenvolvimento é esse? [Morador do Cumbe em entrevista cedida a Queiroz (2007, p. 89-90)].

A análise dos EIAs evidencia que os empreendimentos implantados (carcinicultura e usinas de energia eólica) e especulados (resort) no Cumbe apresentam em seus projetos objetivos e justificativas voltados à promoção do desenvolvimento econômico da região, destacando a geração de empregos diretos e indiretos. Os projetos citam, ainda, sua importância nas questões econômicas e sociais do município de Aracati, onde está situada a comunidade.

O crescimento econômico trazido por tais empreendimentos é destacado na imprensa local como um propulsor da qualidade de vida na região. Isso pode ser visto, por exemplo, na matéria "Aracati, berço da história e do desenvolvimento", do jornal
Diário do Nordeste (2009, p. 3), a qual destaca algumas conquistas notáveis para o desenvolvimento do município, como a instalação de usinas eólicas:

\begin{abstract}
Aracati, um município que nasceu para ser grande e admirado [...] Atualmente, as conquistas são notáveis, repletas de avanços fundamentais para a melhoria da qualidade de vida da comunidade [...] Aracati terá, em breve, o maior parque de geração eólica do País e um dos maiores do mundo. Serão instalados na orla do município aproximadamente 100 aerogeradores, colocando à disposição grande volume de energia eólica.
\end{abstract}

Tal fato ilustra a importância do desenvolvimento econômico como critério de êxito na sociedade e a relação desse fator como instrumento de melhoria dos padrões de vida (Bresser-Pereira, 2008).

No EIA do resort que seria implantado, por exemplo, cita-se a maior circulação de dinheiro no município, "o que certamente iria gerar crescimento econômico e melhoria dos índices sociais" (GEOCONSULT, 2008). O estudo repete e fundamenta tal argumento na ampliação da oferta de empregos na comunidade. Tal discurso é reiterado nos RAS da empresa de Energia Eólica (GEOCONSULT, 2002). O EIA da carcinicultura salienta, ainda, a falta de estrutura da região e a necessidade de desenvolvê-la com a implantação de indústrias (Ribeiro \& Tasiaux, 2006).

A melhoria dos índices sociais é associada, portanto, ao crescimento econômico da região. A perspectiva defendida por Bresser-Pereira (2008) afirma que o aumento de renda per capita reflete necessariamente em mudanças estruturais, culturais e institucionais. Entretanto, a utilização dos conceitos de crescimento econômico e desenvolvimento como sinônimos foi desmistificada após a década de 1960, 
quando a industrialização dos países subdesenvolvidos não refletiu no maior acesso das populações pobres a bens materiais e culturais (Veiga, 2008).

Assim como nos países periféricos, o maior fluxo de capital na comunidade investigada não refletiu na melhoria da qualidade de vida dos moradores. Tal fato se deve principalmente pela má distribuição da renda gerada pelos empreendimentos, ilustrada, por exemplo, no discurso de uma moradora acerca das fazendas de carcinicultura implantadas na região:

A carcinicultura é muito forte aqui na nossa comunidade, mas a maior captação de renda dessa carcinicultura não vai para as pessoas que moram aqui, mas sim para um ou dois empresários que exploram o trabalho das pessoas daqui. A comunidade só fica com seus míseros salários, né? (Moradora em entrevista concedida à autora; em setembro de 2016).

A abordagem do desenvolvimento como liberdade transcende a simples constatação de aumento de renda ou PIB como expressão do desenvolvimento, tendo em vista que o crescimento econômico não é um fim em si mesmo. Para Sen (2000), a ampliação da renda, por exemplo, desempenha função instrumental na promoção da melhoria da realidade social, mas precisa ser analisada em conjunto com outros aspectos. A realidade social, entretanto, é ignorada nos EIA-RIMAs. Tais estudos não trazem uma descrição abrangente da comunidade, ignorando referências aos traços culturais, à organização social e às atividades tradicionais que sempre garantiram sustento e subsistência das famílias (Pinto et al., 2014). A descrição da região do Cumbe é resumida a um "território vazio", formado por pessoas carentes que necessitam da instalação de tais empreendimentos, devido à deficiência de oportunidades de emprego (GEOCONSULT, 2008).

$\mathrm{O}$ uso da carência de empregos e receitas públicas como condição de força para impor práticas que desencadeiam impactos socioambientais e regressão dos direitos sociais é conceituado por Acselrad (2010) como chantagem locacional, isto é, as empresas pressionam os governos e as comunidades com a ameaça de buscar outro lugar para se instalarem, o qual receberá todos os supostos benefícios levados pelo empreendimento. Assim, as descrições das comunidades são executadas de modo a reforçar tal argumento.

Assim como no Cumbe, tal aspecto foi observado por Menestrino \& Parente (2011) em pesquisa sobre a construção de hidrelétricas em territórios tradicionais no Estado de Tocantins. Na ocasião, os EIAs trataram as populações, principalmente as do meio rural, como atrasadas. Seriam, portanto, as hidrelétricas promotoras do progresso, as quais inseririam as comunidades em processo de crescimento e desenvolvimento.

No entanto, o conceito de "atraso" utilizado nos EIAs do Cumbe e das comunidades tradicionais do Tocantins atingidas pelas hidrelétricas é derivado de uma abordagem etnocêntrica, de cunho urbano-industrial, e desconhece as particularidades e as especificidades que constituem distintos modos de vida.

Além do etnocentrismo empregado, a superficialidade denotada à análise dos aspectos sociais das comunidades nos EIAs é decorrente da priorização da razão utilitária da questão ambiental em tais estudos. Desse modo, encara-se o meio ambiente como uno e composto estritamente de recursos materiais, sem conteúdos socioculturais específicos e diferen- 
ciados (Acselrad, 2010). Entretanto, sendo o meio ambiente múltiplo em qualidades socioculturais, este apresenta distintas significações e lógicas de uso, conforme os padrões das distintas sociedades e culturas (Acselrad, 2010). Inviabiliza-se, portanto, uma satisfatória análise ambiental sem a inclusão de aspectos que abranjam as características socioculturais das populações.

A necessidade de tais aspectos são novamente ilustradas no estudo de Menestrino \& Parente (2011), no qual as comunidades ribeirinhas foram descritas como pequenos agricultores ou agricultores de subsistência, e não como grupos pertencentes a povos tradicionais. Assim, as formas de compensação utilizadas pelo empreendimento em questão não levou em conta as especificidades do modo de vida tradicional, e a terra tradicionalmente ocupada deixou de ter seu valor de uso, passando a ter um valor de troca e, portanto, transformando-se em mercadoria.

A superficialidade da análise das questões sociais das comunidades nos EIAs é, ainda, levantada no trabalho de Oliveira (2010) acerca dos impactos da pavimentação de uma rodovia sobre um território indígena localizado no Mato Grosso do Sul. O autor atesta que os impactos sociais negativos (como preconceitos étnico-raciais, doenças decorrentes da inalação de poeira e do estresse causados durante as obras e atropelamentos com vítimas fatais) seriam evitados se previstos no EIA do empreendimento. Com base nos supracitados exemplos, é possível inferir sobre a importância de EIAs que abranjam também questões sociais, em conformidade com as questões econômicas e ambientais, as quais compõem o tripé do desenvolvimento sustentável (Veiga, 2008).
Uma única referência a esses aspectos foi observada no EIA da empresa carcinicultora, em que se menciona a garantia da construção de novas casas, de cobertura de saneamento básico e de energia para toda a região (Ribeiro \& Tasiaux, 2006). A efetividade de tais promessas delineariam a eliminação de privações de liberdades substantivas, o que representaria um avanço no desenvolvimento da região. Entretanto, cerca de 20 anos após a instalação do empreendimento, percebe-se que tais promessas não foram efetivadas, o que constitui ausência de garantias de transparência, uma liberdade instrumental.

As liberdades instrumentais são analisadas a seguir, de acordo com sua função na constituição do papel de agente dos atores sociais cumbenses.

\subsection{Desenvolvimento para quem? A privação das liberdades instrumentais}

A liberdade não é apenas o fim primordial do desenvolvimento, mas é também o seu principal meio. Como discutido anteriormente, segundo Sen (2000), os meios para o desenvolvimento são as liberdades instrumentais, analisadas por meio das facilidades econômicas, das oportunidades sociais, das liberdades políticas, das garantias de transparência e da segurança protetora.

\subsubsection{Facilidades econômicas}

"As facilidades econômicas são as oportunidades que os indivíduos têm para utilizar recursos econômicos com propósitos de consumo, produção ou troca", ou seja, são a criação de condições que permitam a inserção dos indivíduos no mercado 
(Sen, 2000, p. 55). São alcançadas, portanto, com as garantias de renda por meio do trabalho.

No Cumbe, as expectativas da comunidade quanto à geração de renda se dão principalmente em torno do emprego formal. Essas esperanças são alimentadas pelo discurso veiculado pelos representantes dos empreendimentos quanto à ampla oferta de empregos que seriam gerados mediante sua implantação no território cumbense.

Entretanto, tais expectativas da comunidade são frustradas logo após o início das operações. Além do vínculo empregatício muitas vezes não ser formalizado, o emprego de mão de obra cumbense ocorreu apenas na fase de construção dos empreendimentos. Após encerradas as obras, os postos de trabalho exigiram maiores graus de qualificação, necessitando importação de mão de obra, dado que a empresa e o Estado não dispõem de cursos para a comunidade. Situação semelhante foi identificada por Rozendo et al. (2014) na implantação dos parques eólicos no Rio Grande do Norte. No Cumbe, tais dados são reiterados por Ribeiro (2013, p. 105), que trata especificamente dos parques eólicos:

[...] o índice significativo de oportunidade de emprego na comunidade aconteceu durante a implantação do parque, pois os postos de trabalhos não exigiam uma qualificação profissional mais acurada - serventes, ajudante de serviços gerais, carregadores, enfim, trabalhadores braçais. Por outro lado, os postos atuais de trabalho exigem um alto grau de formação profissional, a exemplo de engenheiros e técnicos de nível médio, sendo necessário, portanto, a importação de mão de obra.

No caso da carcinicultura, foram gerados seis vezes menos empregos que o prometido. Justifica-se tal fato pelo fechamento de algumas fazendas após infecções virais desencadeadas pela superpopulação de camarões nos viveiros. A superlotação dos viveiros deve-se à demanda dos produtores por uma produtividade crescente, a qual, ao ultrapassar a capacidade de suporte do ambiente, acarreta a contaminação do produto e a perda total da produção (Nogueira et al., 2009).

Além disso, nas entrevistas há várias referências às dificuldades que os moradores têm para se adaptarem às formas de trabalho estabelecidas nesses empreendimentos, abandonando os postos de trabalhos existentes. Alguns trabalhadores perceberam que a lógica empregada nas fazendas destoa intensamente do modo de vida com o qual estão ambientados e, por causa disso, retornaram à pesca e à catação de crustáceos. Ao retornarem às práticas tradicionais, esses trabalhadores identificaram que a prática das fazendas carcinicultoras de despejar elementos químicos sem tratamento no ambiente cumbense desencadeou, por exemplo, a mortandade do manguezal (Nogueira et al., 2009).

A importância de tal ecozona no equilíbrio ecossistêmico, principalmente por causa da função de berçário de espécies marinhas e fluviais e da disponibilidade de espécies, inclusive as economicamente importantes, foi intensamente afetada. As fazendas de carcinicultura interferiram negativamente nas facilidades econômicas das famílias que dependiam do manguezal para sobreviver. Além disso, o desemprego nas fazendas carcinicultoras que foram à falência, somado ao desaparecimento de espécies que sustentam as atividades tradicionais, contitui um efeito debilitador da liberdade, da iniciativa e das habilidades dos indivíduos (Sen, 2000).

A privação de facilidades econômicas é verificada também em relação aos parques eólicos. A instalação dos parques impediu o acesso dos 
cumbenses à praia, impactando, portanto, a pesca marinha. Para prosseguir com a atividade, os pescadores precisaram se comprometer por meio do Termo de Ajustamento de Conduta (TAC), responsabilizando-se por todo e qualquer eventual risco ocasionado pelos aerogeradores que ocupam o caminho de acesso ao território anteriormente livre. Desse modo, tornou-se possível continuar a atividade pesqueira no mar. No entanto, atualmente a maioria dos pescadores prefere acessar o mar pelo estuário e evitar as dunas, visto que se deve solicitar permissão de acesso à praia mediante identificação nas portarias da empresa de geração de energia eólica.

De forma geral, as atividades econômicas foram substituídas por atividades que desconsideraram a heterogeneidade sociocultural e econômica da comunidade (Queiroz, 2007). Ilustra-se tal aspecto com a substituição da pesca e da mariscagem, por exemplo, por atividades diretamente ligadas aos empreendimentos:

Eles alegavam que ia ter o desenvolvimento, que o emprego da gente de tirar um búzio, um marisco, era feio, era sujo, a lama fede, a cata do caranguejo não dá dinheiro... e trabalhar com eles ia ter salário, ia ter carteira assinada... (Moradora em entrevista concedida à autora em setembro de 2016).

Tal substituição foi desencadeada tanto pelo discurso progressista, que iludiu parte da comunidade, quanto pelos impactos socioambientais que interferiram nas atividades tradicionais. De qualquer forma, há limitação de escolhas quanto às atividades econômicas, o que delinea a privação de liberdade.

As atividades tradicionais, além de permitirem a inclusão da maior parte das famílias cumbenses no mercado, são, ainda, atividades de subsistência. Assim, os impactos nas atividades tradicionais refletem diretamente no regime alimentar da comunidade, que após a implantação dos empreendimentos passou a não ser mais capaz de garantir sua subsistência (Nogueira et al., 2009). Tal fato designa a insegurança alimentar, uma privação de liberdade substantiva.

\subsubsection{Oportunidades sociais}

As oportunidades sociais podem ser sintetizadas como condições instituídas na sociedade que permitem a atuação dos atores sociais em frentes econômicas e políticas (Sen, 2000). Constatando-se a relevância da saúde e da educação como condicionantes da atuação dos indivíduos em tais frentes, analisou-se como esses elementos foram modificados com a inserção dos empreendimentos na comunidade.

Mediante análise da relação entre os empreendimentos e a saúde da comunidade, percebe-se que os impactos são negativos. Trabalhadores da carcinicultura estão expostos a um ambiente de trabalho termicamente e sonoramente desconfortável, com risco de acidentes e lesões de pele causados por substâncias químicas utilizadas no processo produtivo, além de estarem sujeitos a lesões ocasionadas por esforço repetitivo e a problemas respiratórios decorrentes da inalação de gases irritantes. Nogueira et al., (2009) identificaram, ainda, sintomas de tontura, falta de ar, sudorese intensa, palidez e desmaios, caracterizando choques térmicos decorrentes da entrada e saída dos trabalhadores no ambiente refrigerado onde estão dispostos os camarões antes 
da etapa de higienização, em que a temperatura tem média de $38^{\circ} \mathrm{C}$.

Quanto às eólicas, estudos anteriores em outras localidades (Moreira et al., 2013) alertam sobre problemas respiratórios decorrentes do intenso tráfego de veículos na comunidade, principalmente na instalação dos parques. A longo prazo, devido à proximidade às casas, prevê-se que os ruídos provenientes dos geradores causem falta de sono, náuseas, tonturas, dores de cabeça, aumento da pressão arterial e agressividade.

Outro risco à saúde é decorrente do tratamento de água executado pela CAGECE, uma vez que a água que chega às casas da comunidade tem alto teor de cloro, o que pode provocar riscos a longo prazo por conter em sua composição subprodutos potencialmente prejudiciais à saúde, como os trihalometanos (Meyer, 1994). Destaca-se, ainda, a ausência de condições adequadas à disposição de esgotos, tendo em vista que fossas são soluções paliativas e podem ocasionar a poluição de lençóis freáticos. Além disso, percebe-se que, além dos supracitados impactos negativos à saúde da comunidade, a instalação dos empreendimentos não resultou na melhoria do atendimento local à saúde, dado que o posto de saúde continuou apresentando condições precárias.

Quanto à educação, a ideia propalada pelos grandes empreendimentos acerca dos benefícios da modernidade e do atraso das práticas tradicionais é refletida e reforçada na escolarização. Essas características são evidenciadas nas entrevistas, por meio das quais é relatada a inferiorização da identidade pesqueira no ambiente escolar:

A escola não fala da gente, quando fala é de forma negativa. A própria escola diz "menino, se tu não estudar, tu vai ser igual ao teu pai pescador. Tu quer ser igual ao teu pai catador de caranguejo?!' (Pescador em entrevista concedida à autora em setembro de 2016).

Embora a escolaridade seja incentivada pelos educadores como um meio de promover uma realidade diferente da vivenciada pelas famílias que desempenham as atividades tradicionais do Cumbe, isso se faz em um contexto de subalternização de sua cultura. Essa depreciação se revela sob diferentes formas, como na escolarização e nos EIA-RIMAs, que tornam invisíveis as práticas e seus povos; como afirmou a Geoconsult em seu documento, os locais de instalação dos empreendimentos são "territórios vazios". Essas maneiras de produção da inexistência e ou da subalternidade operam de modo debilitador das liberdades.

Sen (2000) mostra a importância da autoestima (poder de agir sobre si) no desenvolvimento da capacidade de agência. $\mathrm{O}$ que não existe ou que está a reboque não pode ter autonomia, estando, portanto, impedido de desenvolver sua capacidade e agência.

\subsubsection{Liberdade política}

São consideradas questões referentes à liberdade de expressão política, ao posicionamento do poder público diante dos conflitos entre a comunidade e os empresários e aos aspectos voltados ao conflito interno.

O descaso do poder público perante as alterações desencadeadas pelos grandes empreendimentos demonstra sua ausência de imparcialidade nos conflitos socioambientais. Ilustra-se tal fato por meio da nota $^{3}$ dos moradores do Cumbe, referente aos preju-

\footnotetext{
3 "Reivindicações das Comunidades do Cumbe e Canavieira: [...] diante dos abusos causados pelas empresas de energia eólica BONS VENTOS,
} 
ízos constatados na instalação dos parques eólicos. Os moradores destaracam a atuação ineficiente de setores dos governos municipal, estadual e federal com a anuência de obras em Áreas de Preservação Permanente (APP), a ausência de fiscalização quanto aos impactos ocasionados e o licenciamento de obras que permitiram agressões aos patrimônios históricos, sociais e ambientais da comunidade do Cumbe.

Tal nota foi publicizada a fim de justificar os protestos comunitários que decorreram de tais conflitos. As reivindicações da comunidade ocorreram sob ameaças de interferência da unidade militar que atende à região, e uma das principais lideranças comunitárias foi ameaçada de sequestro e incluída no Programa de Proteção às Defensoras e Defensores de Direitos Humanos do Governo Federal (O Estado de S. Paulo, 2013).

Tais episódios marcam, portanto, intimidações às lideranças comunitárias, que constituem limitações à liberdade política. Outro aspecto que contribui para tal limitação é delineado com a responsabilização e a criminalização de pescadores e líderes comunitários, resultantes dos protestos e dos processos de resistência contra os impactos ocasionados pelo modelo desenvolvimentista imposto à comunidade.

Um dos episódios tem relação com a ocupação de uma área de carcinicultura abandonada, por pescadores e pescadoras que decidiram construir ali um cultivo comunitário de ostras. Isso resultou em conflito com o dono da terra, que solicitou a reintegração de posse da área anteriormente abandonada. A juíza, que foi afastada após o episódio por conta de suspeita de favorecimento ao carcinicultor (Diário do Nordeste, 2015), determinou cumprimento da liminar com reintegração de posse, que contou com ações desproporcionais da polícia do Comando Tático Rural (COTAR) e do Policiamento Ostensivo Geral (POG). Extremamente repressivas e fechadas ao diálogo, tais forças atuaram com balas de borracha e bombas de gás contra os pescadores e as pescadoras, destruindo, ainda, 42 mil ostras que garantiriam o sustento das famílias.

Com as revoltas geradas por tal episódio, a comunidade mobilizou espaços de discussão acerca dos impactos da carcinicultura em seu modo de vida. Entretanto, tal mobilização resultou na notificação de lideranças comunitárias para comparecimento à Delegacia Regional de Aracati, evidenciando mais um episódio de intimidação e, consequentemente, de restrições à liberdade de expressão política.

Tais restrições são provenientes, ainda, do conflito interno instituído na comunidade com a instalação dos empreendimentos e intensificado com os trabalhos de demarcação do território tradicional quilombola executados pelo Instituto Nacional de Colonização e Reforma Agrária (INCRA), etapa posterior à certificação quilombola pela Fundação Palmares.

Segundo Brissac (2017), a intensificação do conflito interno está diretamente ligada à mobilização de parte da comunidade contra a regularização da política quilombola na região pelos grupos econômicos cujos interesses são contrariados com a demarcação do território tradicional. O autor relata que o posicionamento de parte da comuni-

CANOA QUEBRADA E ENACEL, e pela atuação ineficiente de setores dos governos municipal, estadual e federal que permitiram de forma inescrupulosa, a prática de agressões aviltantes ao patrimônio histórico, social e ambiental da comunidade do Cumbe e suas imediações (...). Pela ausência de fiscalização e atuação no âmbito municipal, estadual e federal de órgãos como SECRETARIAS MUNICIPAIS DE MEIO AMBIENTE E DE OBRAS, IPHAN, IBAMA, SEMACE, IDACE, MPF e OUVIDORIA DO PODER JUDICIÁRIO [...]” 
dade (representada pela Associação de Moradores de Cumbe e Canavieira) se deu, sobretudo, pela argumentação dos empresários da carcinicultura baseada na atribuição de características de fraude e retrocesso às comunidades quilombolas. Desse modo, o reconhecimento quilombola significaria "algo como condenar todo o grupo ao atraso e ao subdesenvolvimento" (Brissac, 2017, p. 25).

Temendo, portanto, ser prejudicada com a regularização das políticas quilombolas no Cumbe, a Associação de Moradores de Cumbe e Canavieira promoveu ações diretas no intuito de prejudicar o andamento das questões voltadas a tal aspecto. Relatam-se, por exemplo, tentativas de impedir a demarcação e a titulação das terras tradicionais por meio de pressões aos trabalhadores do INCRA. São também relatados bloqueios às estradas de acesso à comunidade, a fim de impedir a entrada de especialistas que auxiliariam ações da Associação Quilombola do Cumbe, além de perseguições àqueles que se autoreconhecem quilombolas, por meio de ameaças e restrições à locomoção pela comunidade.

\subsubsection{Garantias de transparência}

A não utilização de segredos e a clareza, elementos necessários nas interações sociais, constituem as garantias de transparência (Sen, 2000). Com base na análise das supracitadas privações de facilidades econômicas, percebe-se que a inverdade constatada no discurso dos empreendimentos acerca do enorme contingente de empregos que seriam gerados na região constitui privação da liberdade instrumental analisada, baseada na confiança entre os atores.
Ainda acerca da questão da empregabilidade, os empreendimentos garantiam em seus discursos a disponibilização de condições de trabalho melhores que as encontradas nas atividades tradicionais. Entretanto, quando contratados, os indivíduos se depararam com formas precárias de trabalho, que implicaram riscos à saúde de natureza física, química, biológica e ergonômica (Nogueira et al., 2009).

Nos EIA-RIMAs das eólicas, cita-se que as empresas propulsionarão o turismo na região. Considerando esta uma atividade que proporcionaria inclusão social, tal fator desencadeou aprovação de grande parte da comunidade em relação à instalação dos empreendimentos. No entanto, a chegada dos parques eólicos implicou no aterro de lagoas periódicas e na privação do acesso à praia, tornando inacessíveis os ambientes que constituiriam atrativos turísticos da região, contrariando o discurso propalado anteriormente. A privação das garantias de transparência é constatada, ainda, nos EIAs das carciniculturas. As obras de saneamento prometidas para a comunidade não foram cumpridas nem mesmo nas próprias fazendas, tendo em vista a ausência de tratamento dos efluentes dos viveiros de camarão, exigindo interferência do órgão ambiental para serem executadas.

\subsubsection{Segurança protetora}

A segurança protetora pode ser conceituada como uma rede de segurança social constituída por disposições institucionais que assegurem que a população não seja afetada pela miséria (Sen, 2000). Um claro exemplo de segurança protetora é o seguro desemprego, instrumento de assistência temporária concedido ao trabalhador desempregado. Para ser contemplado 
com tal benefício, ele necessita da formalização por meio da assinatura da carteira de trabalho.

No entanto, na região estudada, tal formalização muitas vezes não ocorre, principalmente nas micro e pequenas empresas carcinicultoras, como relatado nas entrevistas feitas por Nogueira et al. (2009, p. 44) com funcionários das fazendas:

A empresa tem 30 funcionários, mas a metade é sem carteira assinada. Eu estava com carteira assinada - foi dado baixa agora há pouco tempo. Porque estava pagando muitos impostos, era uma confusão medonha.

O desemprego desencadeado na comunidade, devido aos impactos dos efluentes da carcinicultura no ambiente de trabalho dos pescadores e catadores de crustáceos (os quais desencadearam mortandade dos recursos utilizados em tais práticas), também demandou a provisão de instrumentos de segurança protetora, como a criação de empregos públicos de emergência para gerar renda aos necessitados. Entretanto, tal instrumento não foi viabilizado, caracterizando mais uma forma de privação de liberdade instrumental.

\subsection{O aspecto da condição de agente como fim do desenvolvimento}

A discussão anterior tratou dos elementos que compõem as liberdades instrumentais e foi elaborada separadamente para fins didáticos. Contudo, Sen (2000) considera que há um encadeamento e uma suplementação entre as diferentes formas de liberdade. Para o autor, as liberdades têm caráter constitutivo (intrínseco) e, ao mesmo tempo, instrumental. Constitutivo porque a "liberdade humana deve ser o objetivo supremo do desenvolvimento" (Sen, 2000, p. 10). Instrumental pois a expansão de determinadas liberdades tem projeções sobre outras formas de liberdade, o que tem uma utilidade prática para a melhora da vida dos indivíduos.

A liberdade de ter acesso à educação pode ampliar a liberdade de participação política. O exercício desta, por sua vez, pode habilitar os indivíduos a enfrentarem situações de privação. Por isso, a ampliação das liberdades é condição fundamental na produção da agência. Entende-se por papel de agente a capacidade dos indivíduos de participar de ações econômicas, sociais e políticas e de ocasionar mudanças por meio de seus próprios valores e objetivos (Sen, 2000).

Com base nas discussões anteriores, percebeu-se a relação entre as privações de liberdade na Comunidade do Cumbe, por meio da violação de confiança nas relações entre os empreendedores e a comunidade, isto é, pela ausência de garantias de transparência em vários aspectos.

No caso das eólicas, constataram-se a falta de clareza quanto à ocupação do território, com a privatização de praias, a dificultação e/ou o impedimento do acesso dos moradores a locais tradicionalmente ocupados pelas atividades de pesca, além da criação de falsas expectativas sobre a geração de postos de trabalhos e melhoria da infraestrutura local.

No caso da carcinucultura, a restrição de facilidades econômicas é ilustrada pelos seus impactos sobre as atividades tradicionais, dificultando o prosseguimento destas. Tal fato promoveu a organização dos cumbenses em frentes políticas que reivindicavam a responsabilização dos grandes empreendimentos e a restituição do equilíbrio ecossistêmico, o que asseguraria a continuidade da pesca e a catação de crustáceos. 
Entretanto, como relatado anteriormente, tal organização desencadeou episódios de repressão e intimidação das lideranças comunitárias, o que representa restrições às liberdades de expressão, fundamentais para a liberdade política da comunidade. O descontentamento em relação a tal aspecto pode ser observado no seguinte relato:

Eu hoje vejo muita gente naquela escravidão de pensamento. Por exemplo, pensam "eu tenho que trabalhar para esse carcinicultor, se ele me contratou eu não posso dizer que o mangue é bom, não posso ter minhas alternativas de pensamento, porque eu tô trabalhando na carcinicultura" (Moradora em entrevista concedida à autora em setembro de 2016).

Ao analisar o relato, percebe-se, no trecho em que a moradora afirma "não posso ter minhas alternativas de pensamento", a tentativa de controle dos responsáveis pelos empreendimentos sobre as valorações que os cumbenses fazem. Conceber o mangue como algo bom é colocar em xeque as formas de produção da carcinicultura, que se fazem justamente pela destruição daquilo que se está valorando. São processos produtivos que operam em lógicas opostas. Portanto, empregar-se na carcinicultura implica abdicar dessas "alternativas de pensamento", de ter um pensamento autônomo. Implica também "des-envolver-se" e assumir um novo envolvimento: o envolvimento das empresas, como alerta Porto-Gonçalves (2004).

Diante da análise de tais aspectos, percebe-se, portanto, que o desenvolvimento desencadeado pela instalação dos empreendimentos vem resultando na restrição das liberdades dos indivíduos da comunidade, interferindo negativamente no papel de agente dos cumbenses.

\section{Conclusões}

A privação das liberdades instrumentais e, consequentemente, do papel de agente dos moradores do Cumbe pode ser observada em todos os aspectos propostos por Amartya Sen. As facilidades econômicas são privadas com a inviabilização do acesso da comunidade às ecozonas importantes para reprodução das atividades de subsistência e com a precarização de tais ambientes devido aos impactos ambientais. Destaca-se, ainda, que as promessas de geração de emprego e renda são cumpridas somente no momento de instalação dos empreendimentos.

Quanto à privação das oportunidades sociais, destacam-se os impactos na saúde e na educação. Os danos à saúde são evidenciados pela insalubridade nos ambientes de trabalho, bem como pela poluição sonora na região e pelo consumo de água com altos níveis de cloro. Em relação à educação, houve uma modificação da lógica do ensino, em que há a supervalorização da modernidade em detrimento do modo de vida tradicional.

A ausência de liberdades políticas é identificada nos diversos episódios nos quais a população foi coagida, intimidada e criminalizada por causa da atuação na comunidade e do enfrentamento às injustiças ambientais cometidas pelos grandes empreendimentos. Vale ressaltar, ainda, o descaso do poder público em relação aos impactos negativos causados pelos empreendimentos e a conivência do Estado com tal modelo desenvolvimentista, instituindo uma aliança entre empresários e governo e intensificando a invisibilização das formas de uso e ocupação instituídas pelo modo de vida tradicional.

As garantias de transparência foram inviabilizadas, em diversos momentos, pela falta de clareza 
e verdade nos discursos presentes nos EIA-RIMAs. Destacam-se, por exemplo, a supracitada promessa de emprego e renda, a qual não expõe que a maioria dos empregos gerados duraria apenas até a fase de implantação dos empreendimentos; a não constatação do impulsionamento do turismo prometido pelas usinas eólicas; e a não instalação de obras voltadas à melhoria do saneamento básico na região.

Conclusivamente, quanto às privações à segurança protetora, podem ser destacadas a ausência de assistência financeira, decorrente de contratações informais por parte das grandes empresas, e a falta de assistência do poder público, ilustrada pela ausência de criação de projetos que pudessem mitigar o desemprego.

Assim, de acordo com os resultados obtidos, é possível inferir que o discurso desenvolvimentista proferido pelos grandes empreendimentos se mostra inviável na comunidade tradicional do Cumbe. $\mathrm{O}$ crescimento econômico é utilizado como pretexto para a infiltração desses modelos, que impactam o modo de vida tradicional e ignoram os aspectos sociais, culturais e ambientais da região.

Mostra-se necessário, portanto, problematizar o tipo de desenvolvimento levado às comunidades tradicionais, tendo em vista que este pode ilustrar o progresso econômico de grupos empresariais em detrimento dos modos de vida tradicionais, subalternizando-os e os tornando invisíveis, tal como foi diagnosticado na Comunidade do Cumbe.

\section{Agradecimentos}

Gostaríamos de agradecer ao João Luís Joventino do Nascimento (João do Cumbe), bem como às duas associações de moradores da Comunidade do Cumbe, pelas entrevistas cedidas. Agradecemos também ao ecólogo Valter Lacerda Vásquez, pela elaboração do mapa de localização da comunidade, e à estudante de Letras Dandara Caroline da Silva, pela elaboração do resumo em inglês.

\section{Referências}

Acselrad, H. Ambientalização das lutas sociais - o caso do movimento por justiça ambiental. Estudos Avançados, 24(68), 103-119, 2010. doi: 10.1590/S010340142010000100010 .

Bardin, L. Análise de conteúdo. Lisboa: Edições 70, 3. ed., 2001.

Brasil. Decreto $n .^{\circ}$ 5.051, de 19 de abril de 2004. Promulga a Convenção no 169 da Organização Internacional do Trabalho - OIT sobre Povos Indígenas e Tribais. Brasília: DOU de 19/4/2004.

Brasil. Decreto $n .^{\circ}$ 6.040, de 7 de fevereiro de 2007. Institui a Política Nacional de Desenvolvimento Sustentável dos Povos e Comunidades Tradicionais. Brasília: DOU de 7/2/2007.

Bresser-Pereira, L. C. Crescimento e desenvolvimento econômico. Fundação Getúlio Vargas, 2008. Disponível em: $<$ http://www.bresserpereira.org.br/Papers/2007/07.22. CrescimentoDesenvolvimento.Junho19.2008.pdf $>$. Acesso em: 01 abr. 2017.

Brissac, S. Parecer Técnico sobre os conflitos relacionados com a titulação da comunidade remanescente de quilombos do Cumbe, no município de Aracati/CE. Parecer Técnico $n^{\circ}$ 3/2017. Limoeiro do Norte: Ministério Público Federal, 2017.

Diário do Nordeste. Aracati, berço da história e do desenvolvimento. Fortaleza, Caderno Regional, p. 3, 2009.

Diário do Nordeste. TJCE afasta juíza da comarca de Aracati. Fortaleza, 2015. Disponível em: $<$ http://diariodonordeste. verdesmares.com.br/cadernos/cidade/tjce-afasta-juiza-da-comarca-de-aracati-1.1273240>. Acesso em: 15 abr. 2017. 
Diegues, A. C.; Arruda, R. S. V. Biodiversidade e comunidades tradicionais no Brasil. São Paulo: NUPAUB-USP/ PROBIO-MMA/CNPq, 1999.

Foster, G. Traditional cultures and the impact of technological change. New York: Harper and Brothers, 1962.

Furtado, C. O mito do desenvolvimento econômico. Rio de Janeiro: Paz e Terra, 1974.

GEOCONSULT — Consultoria Geologia \& Meio Ambiente Ltda. Relatório Ambiental Simplificado (RAS) do Parque Eólico Bons Ventos Canoa Quebrada, Aracati. Fortaleza: SEMACE, 2002.

GEOCONSULT - Consultoria Geologia \& Meio Ambiente Ltda. Estudo de Impacto Ambiental (EIA) do condomínio Canoa Beachfront Resort. Fortaleza: SEMACE, 2008.

Mattedi, M. A. Pensando com o desenvolvimento regional: subsídios para um programa forte em desenvolvimento regional. Revista brasileira de desenvolvimento regional, 2(2), 59-105, 2015. doi: 10.7867/2317-5443.2014v2n2p059-105.

Mello, C. C. do A.; Bezerra, G. das N.; Acselrad, H. O que é justiça ambiental. Rio de Janeiro: Garamond, 2009.

Menestrino, E.; Parente, T. G. O estudo das territorialidades dos povos tradicionais impactados pelos Empreendimentos Hidrelétricos no Tocantins. Brazilian Geographical Journal: Geosciences and Humanities research medium, 2(1), 1-19, 2011. Disponível em: http://www.seer.ufu.br/index. php/braziliangeojournal/article/view/9157/7570.

Meyer, S. T. O uso de cloro na desinfecção de águas, a formação de trihalometanos e os riscos potenciais à saúde pública. Cadernos de Saúde Pública, 10(1), 99-110, 1994. doi: 10.1590/S0102-311X1994000100011.

Moreira, R. N.; Vidal, F. A. B.; Viana, A. F.; Oliveira, D. A. B. de. Energia eólica no quintal da nossa casa?! Percepção ambiental dos impactos socioambientais na instalação e operação de uma usina na comunidade de sítio do Cumbe em Aracati-CE. Revista de gestão ambiental e sustentabilidade, 2(1), 45-73, 2013. Disponível em: http://www.revistageas. org.br/ojs/index.php/geas/article/view/39/pdf.

Nascimento, J. L. J. Processos educativos: as lutas das mulheres pescadoras do mangue do Cumbe contra o racismo ambiental. Fortaleza, Dissertação (Mestrado em Educação
Brasileira) - UFC, 2014.

Nogueira, F. N. A.; Rigotto, R. M.; Teixeira, A. C. de A. O agronegócio do camarão: processo de trabalho e riscos à saúde dos trabalhadores no município de Aracati/Ceará. Revista brasileira de saúde ocupacional, 34(119), 40-50, 2009. doi: 10.1590/S0303-76572009000100005.

O Estado de S. Paulo. Professor que participou de protestos diz que escapou de sequestro. São Paulo, 2013. Disponível $\mathrm{em}:<\mathrm{http} / / /$ economia.estadao.com.br/noticias/geral,professor-que-participou-de-protestos-diz-que-escapou-de-sequestro,155334e>. Acesso em: 15 abr. 2017.

Oliveira, J. E. de. Sobre a necessidade do trabalho antropológico para o licenciamento ambiental: avaliação dos impactos socioambientais gerados a partir da pavimentação asfáltica da Rodovia MS-384 sobre a comunidade Kaiowa de Ñande Ru Marangatu. Revista História em Reflexão, 4(7), 1-24, 2010. Disponível em: http://ojs.ufgd.edu.br/index.php/ historiaemreflexao/article/viewFile/754/470.

Pinto, M. F.; Nascimento, J. L. J. do; Bringel, P. C. F.; Meireles, A. J. de A. Quando os conflitos socioambientais caracterizam um território? Gaia Scientia, 8(2), 271-288, 2014. doi: 10.21707 /gs.v8i2.22721.

Porto-Gonçalves, C. W. O desafio ambiental. Rio de Janeiro: Record, 2004.

Queiroz, L. de S. Na vida do Cumbe há tanto mangue: as influências dos impactos socioambientais da carcinicultura no modo de vida de uma comunidade costeira. Fortaleza, Dissertação (Mestrado em Desenvolvimento e Meio Ambiente) - UFC, 2007.

Ribeiro, G. L. Parques eólicos - impactos socioambientais provocados na região da praia do Cumbe, no município de Aracati, Ceará. São Paulo, Tese (Doutorado em Geografia) - UNESP, 2013.

Ribeiro, M. G.; Tasiaux, M. C. Estudo de impacto ambiental (EIA) Aquaplace Aquacultura. Aracati: SEMACE, 2006.

Rozendo, C. Políticas Ambientais, agricultura familiar e recomposição dos espaços rurais na Região Metropolitana de Curitiba. Curitiba, Tese (Doutorado em Meio Ambiente e Desenvolvimento) - UFPR, 2006.

Rozendo, C.; Ferraz, E.; Bastos, F. Que bons ventos as 
trazem? A investida das usinas eólicas e a reconfiguração dos territórios rurais no Estado do Rio Grande do Norte: desafios e perspectivas. In: Anais do Encontro Anual da ANPOCS. Caxambu, 27 de out., 2014.

Sachs, I. Rumo à ecossocioeconomia: Teoria e prática do desenvolvimento. São Paulo: Cortez, 2007.

Sachs, I. Caminhos para o desenvolvimento sustentável. Rio de Janeiro: Garamond, 3. ed., 2008.
Santos, B. de S. Renovar a teoria crítica e reinventar a emancipação social. São Paulo: Boitempo, 2007.

Sen, A. K. Desenvolvimento como liberdade. São Paulo: Companhia das letras, 2000.

Veiga, J. E. da. Desenvolvimento sustentável: o desafio do século XXI. Rio de Janeiro: Garamond, 3. ed., 2008. 